\title{
New Primary Tumor
}

National Cancer Institute

\section{Source}

National Cancer Institute. New Primary Tumor. NCI Thesaurus. Code C156806.

A finding indicating the development of a tumor in a patient with a history of a previously diagnosed tumor with a different histopathologic profile in another anatomic site as compared to the most recent one. 